\title{
Radiation exposure benefit of a lead cap in invasive cardiology
}

\author{
E Kuon, J Birkel, M Schmitt, J B Dahm
}

See end of article for authors' affiliations

\section{Correspondence to}

Dr Eberhard Kuon, Klinik

Fraenkische Schweiz,

Feversteinstr 2, D-91320

Ebermannstadt, Germany;

eberhard.kuon@

klinik-fraenkische-schweiz.de

Accepted 19 May 2003

\begin{abstract}
Background: Occupational head exposure to radiation in cardiologists may cause radiation induced cataracts and an increased risk of brain cancer.

Objective: To determine the effectiveness of $0.5 \mathrm{~mm}$ lead equivalent caps, not previously used in invasive cardiology, in comparison with a $1.0 \mathrm{~mm}$ lead equivalent ceiling mounted lead glass screen.

Design: An anthropomorphic Alderson-Rando phantom was used to represent the patient. Scatter entrance skin air kerma to the operator position (S-ESAK-O) was measured during fluoroscopy for all standard angulations and the S-ESAK-O per dose-area product (DAP) calculated, as applied to the phantom.

Results: Measured mean (SD) left/right anterior oblique angulation ratios of S-ESAK-O without lead devices were 23.1 (10.1), and varied as a function of tube angulation, body height, and angle of incidence. S-ESAK-O/DAP decreased with incremental operator body height by $10(3) \%$ per $10 \mathrm{~cm}$. A $1.0 \mathrm{~mm}$ lead glass shield reduced mean S-ESAK-O/DAP originating from coronary angiography from 1089 (764) to 54 (29) nSv/Gy $\times \mathrm{cm}^{2}$. A $0.5 \mathrm{~mm}$ lead cap was effective in lowering measured levels to 1.8 (1.1) nSv/Gy $\times \mathrm{cm}^{2}$. Both devices together enabled attenuation to $0.5(0.1) \mathrm{nSv} / \mathrm{G} y \times \mathrm{cm}^{2}$. The most advantageous line of vision for protection of the operator's eyes was $\geqslant 60^{\circ}$ rightward.

Conclusions: Use of $0.5 \mathrm{~mm}$ lead caps proved highly effective, attenuating S-ESAK-O to 2.7 (2.0) $\times 10^{-3}$ of baseline, and to $1.2(1.4) \times 10^{-3}$ of baseline where there was an additional $1.0 \mathrm{~mm}$ lead glass shield. These results could vary according to the $x$ ray systems used, catheterisation protocols, and correct use of radiation protection devices.
\end{abstract}

$\mathrm{N}$ o dose of radiation may be considered safe or harmless. ${ }^{1}$ All medical exposure for radiodiagnostic purposes should be kept "as low as reasonably achievable", ${ }^{3}$ and "shielding, attached to either the equipment or the operator, should be used as completely as possible without encumbering the examining physician or ... jeopardising the welfare of the patient". ${ }^{4}$ Nevertheless, practising interventional cardiologists are reported to receive an annual average $x$ ray dose of $1.7 \mathrm{mSv}$ with the use of a thyroid shield, and $3.5 \mathrm{mSv}$ without this protection (both figures include the use of a lead apron). ${ }^{5}$ Their effective dose per procedure varies between 9-50 $\mathrm{Sv}^{6-8}$ Without lead protection, the operator's eyes receive a mean (SEM) entrance skin dose of 165 (97) $\mu \mathrm{Sv}$ per coronary angiography session. ${ }^{14-12}$ The use of lead eyeglasses lowers this level to 37 (15) $\mu \mathrm{Sv} .{ }^{9}{ }^{11}$ The annual head dose sustained by cardiologists may reach $60 \mathrm{mSv}$ a year, and may in some cases exceed the occupational limit of $150 \mathrm{mSv}$ a year recommended for the lens of the eye. ${ }^{13}$ There is current consideration of the risks of radiation induced cataracts ${ }^{814}$ and malignancy, particularly brain cancer. ${ }^{5}$ Until now operators have not used personal protective garments to shield their forehead and brain. The goal of our study was to determine the effectiveness in invasive cardiology of lead equivalent caps $0.5 \mathrm{~mm}$ thick, and to compare this new type of protection with an improved $1.0 \mathrm{~mm}$ lead equivalent glass overcouch shield.

\section{METHODS}

\section{Definitions}

Patient's entrance skin air kerma (ESAK) is the dose to the air in the entrance plane of the patient without backscatter. Entrance skin dose (ESD) includes backscatter and is appropriate for characterisation of deterministic risks for skin lesions. Both are measured in Grays $(\mathrm{Gy}=\mathrm{J} / \mathrm{kg})$. Dose-area product (DAP) is the product of the area of the cross section of an $x$ ray beam and the air kerma averaged over that cross section. The unit is Gray square centimetre $\left(\mathrm{Gy} \times \mathrm{cm}^{2}\right)$.
S-ESAK-O is the scatter entrance skin air kerma to the operator position caused by stray radiation, which is defined as the sum of the following: primary scatter emitted from the patient in all directions, secondary scatter reflected from the walls, and the small fraction of tube housing leakage.

DAP was measured for 122 patients as well as at an anthropomorphic Alderson-Rando phantom. In a second step, we measured S-ESAK-O at this phantom, representing the patient, during fluoroscopy for all standard angulations and calculated S-ESAK-O per DAP.

\section{Equipment}

We employed a digital, single arm Advantx LC + undercouch tube and overcouch image intensifier system (GE Medical Systems, Fairfield, Connecticut, USA) with the following installed in the $x$ ray beam: $0.1 \mathrm{~mm}$ copper filter, $2.9 \mathrm{~mm}$ aluminium filter, and-throughout all measurements-an antiscatter grid. Under conditions of focus image intensifier distance of $1 \mathrm{~m}$, and for a copper absorber $2 \mathrm{~mm}$ thick, the image intensifier entrance dose rates during fluoroscopy were $0.21 \mu \mathrm{Gy} / \mathrm{s}$ for the $23 \mathrm{~cm}$ image intensifier field and $0.30 \mu \mathrm{Gy} / \mathrm{s}$ for the $17 \mathrm{~cm}$ field. During cine acquisition (12.5 frames/s), these values were $0.08 \mu \mathrm{Gy} /$ frame $(23 \mathrm{~cm}$ field $)$. The DAP was measured by an ionisation diamentor, calibrated in situ on the $x$ ray tube (reliability for repetition $<3 \%$; total uncertainty for linearity (60-150 kV) < 5\% (M4, PTW, Freiburg, Germany)).

The electrical charge generated in the ionisation chamber was equivalent to the DAP $\left(\mathrm{Gy} \times \mathrm{cm}^{2}\right)$ and accordingly was directly proportional to the collimated radiation beam passing

\footnotetext{
Abbreviations: DAP, dose-area product; ESAK, entrance skin air kerma; ESD, entrance skin dose; LAO, left anterior oblique; PA, posterior-anterior; RAO, right anterior oblique; S-ESAK-O, scatter entrance skin air kerma to the operator position
} 


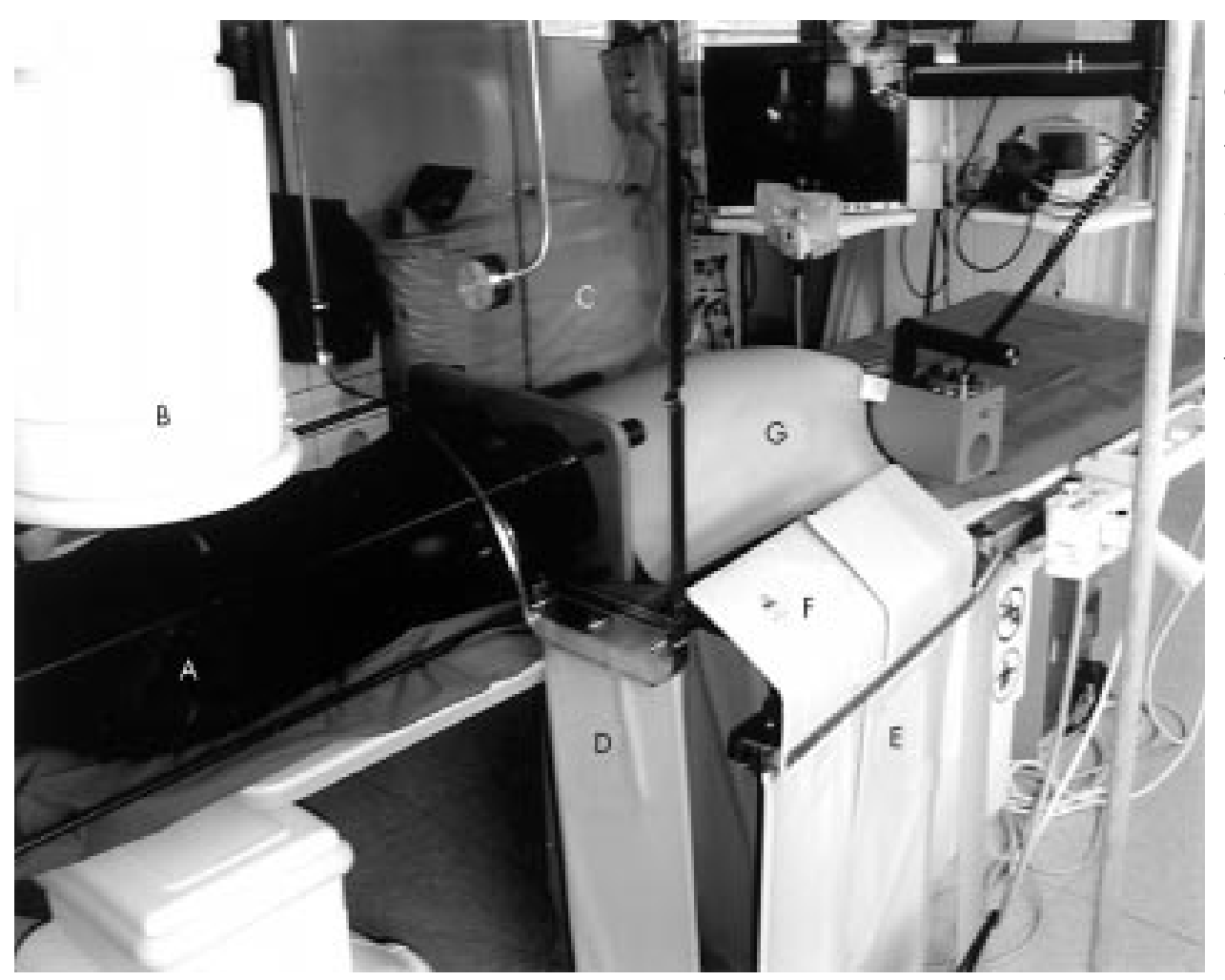

Figure 1 Position of Rando phantom $(A)$; image intensifier $(B)$; articulated ceiling screen $(C)$

lengthened by a lead flap beside the table (D); longitudinal table mounted lead drape (E), enhanced by a top shield $(\mathrm{F})$; and lead cover around the phantom's thighs (G). The detector for scatter radiation in operator's position $(H)$ is directed towards the left side at an angle of incidence of $-40^{\circ}$.

the cross sectional chamber area as well as the patient's body surface area. The company's product specifications declare that the attenuation of the carbonaceous table, including the table cover (Omega 4, type 2181400, GE, Buc cedex, France), is equivalent to $1.2 \mathrm{~mm}$ aluminium, and that the correction factors at $70-90 \mathrm{kV}$ are 1.10 for direct lateral exposures and 0.97 for undercouch exposure perpendicular to the couch.

Complete radiation protection (as supplied by MAVIG, Munich, Germany) was achieved by an articulated ceiling screen $(60 \times 75 \mathrm{~cm})$, lengthened by a flap beside the table $(21 \times 80 \mathrm{~cm}) ; \quad$ a longitudinal table mounted lead drape $(60 \times 80 \mathrm{~cm})$, enhanced by a top shield $(60 \times 20 \mathrm{~cm})$; and a lead cover around the phantom's (patient's) thighs. Each shield showed $1.0 \mathrm{~mm}$ lead equivalence (fig 1). The operator used a cap (Burkhart Roentgen International, St Petersburg, Florida, USA), glasses, apron, and collar (MAVIG, Munich, Germany), all with $0.5 \mathrm{~mm}$ lead equivalence (fig 2). The lead cap weighs approx $1140 \mathrm{~g}$ and offers acceptable wearing comfort.

\section{Cardiac catheterisation procedures}

One interventionist performed 122 diagnostic catheterisations with femoral access. We documented total DAP, DAP from cinematography $\left(\mathrm{DAP}^{\mathrm{C}}\right)$ and fluoroscopy $\left(\mathrm{DAP}^{\mathrm{F}}\right)$, the number of cinegraphic frames, and the time adjusted cinegraphic dose area product per frame. The patients' mean (SD) age was 65 (8) years, $56 \%$ were male and $44 \%$ female, and their body mass index was $28(4) \mathrm{kg} / \mathrm{m}^{2}$.

\section{Characterisation of the patients' in vivo conditions using a Rando phantom}

The first methodological step was to validate the assessment of DAP obtained with the phantom with that received by a patient in an analysis of 122 coronary angiographic examinations. The mean patient $\mathrm{DAP}^{\mathrm{C}} /$ frame $(17 \mathrm{~cm}$ intensifier field) obtained with the phantom did not differ significantly from that measured in vivo: $21.6(7.7) \vee 24.0$ (7.6) Gy $\times \mathrm{cm}^{2}(\mathrm{p}>0.38)$, respectively. Using straight line regression, the correlation coefficient for all the various tube angulations was 0.91 (fig 1).

The second step was to correlate stray radiation to the operator with the DAPs measured on the phantom. The correlation coefficient was 0.99 between S-ESAK-O and DAP in

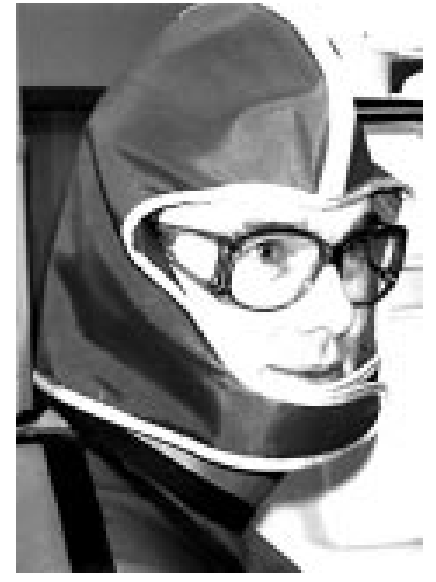

Figure 2 Protective garments with $0.5 \mathrm{~mm}$ lead equivalency: cap, glasses, collar, and apron.

$0^{\circ} / 0^{\circ}$ posterior-anterior ( $\left.\mathrm{PA}\right)$ tube angulation at a table height of $95 \mathrm{~cm}$, and with a dosimeter height of $100 \mathrm{~cm}$ at a distance of $100 \mathrm{~cm}$ from the isocentre. In agreement with other research, S-ESAK-O/DAP increased slightly with $\mathrm{kV}$ and field size (diameter $13-23 \mathrm{~cm}$ ). ${ }^{16}$ In order to diminish the investigator's radiation exposure, we undertook further scatter radiation measurements in fluoroscopy mode.

\section{Data collection}

We conducted measurements of fluoroscopy scatter radiation $(\mu \mathrm{Sv} / \mathrm{h})$ at a male anthropomorphic Alderson-Rando phantom, using a Szintomat 6134 A system (Automess, Ladenburg, Germany). The system was calibrated for a dose intensity range of $100 \mathrm{nSv} / \mathrm{h}$ to $100 \mathrm{mSv} / \mathrm{h}$. For an incident angle of $45^{\circ}$, the measured radiation exposure uncertainty was $<10 \%$. At an operator's position $100 \mathrm{~cm}$ from the isocentre $(60 \mathrm{~cm}$ adjacent to and $80 \mathrm{~cm}$ caudally to the tube), we measured $\mathrm{S}$-ESAK-O in $10 \mathrm{~cm}$ increments within a height range of 140$200 \mathrm{~cm}$ (seven positions), for all 10 standard tube angulations of coronary angiography (fig 1) and for all 11 angles of incidence to the operator (fig 3: $-120^{\circ},-90^{\circ},-60^{\circ},-40^{\circ}$, and $-20^{\circ}$ to the left; $0^{\circ}$; and $+20^{\circ},+40^{\circ},+60^{\circ},+90^{\circ}$, and $+120^{\circ}$ to the right of the operator's front). 

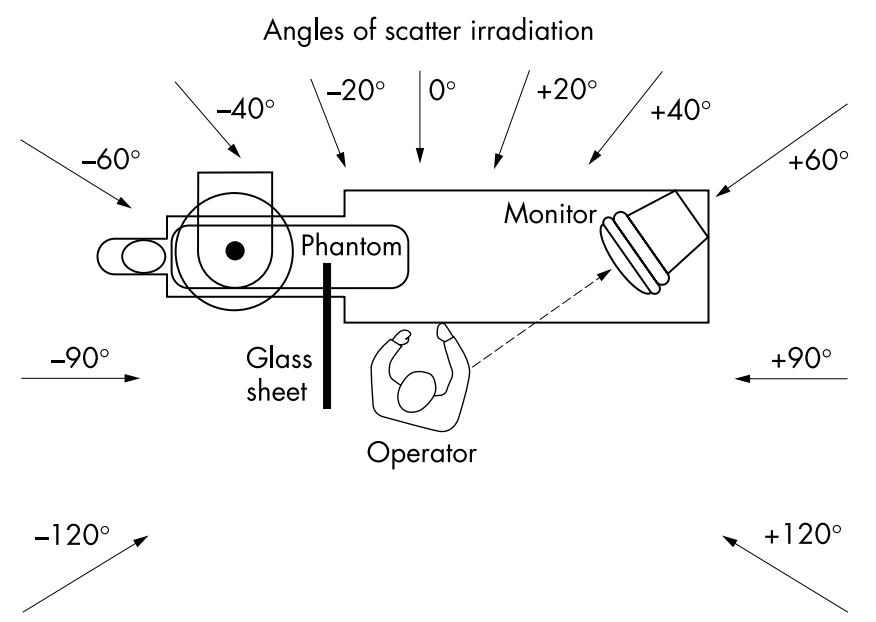

Figure 3 Position of tube, patient's couch, and interventional operator, as well as angles of incidence of the scatter radiation to the operator: $-120^{\circ},-90^{\circ},-60^{\circ},-40^{\circ}$, and $-20^{\circ}$ from the left side; $0^{\circ}$; and $+20^{\circ},+40^{\circ},+60^{\circ},+90^{\circ}$, and $+120^{\circ}$ from the right side to the operator's front.

Measurements were done in four steps: without any radiation protection; with an articulated, ceiling mounted $1.0 \mathrm{~mm}$ lead glass screen lengthened by the lead flap; with a helmet of $0.5 \mathrm{~mm}$ lead equivalence; and with both protection devices together (fig 2). We accordingly undertook a total of 3080 $(7 \times 10 \times 11 \times 4)$ individual measurements.

With measurements based on DAP per second and applied to the phantom, we calculated the ratio of S-ESAK-O to DAP at all heights for each angulation and angle of incidence to the operator. We then took into account the partial DAP contributions of the respective tube angulation to the overall in vivo DAP (6.5 $\mathrm{Gy} \times \mathrm{cm}^{2}$ ) obtained for the patients during coronary angiography. ${ }^{12}$ On this basis, we finally computed the local scatter-ESAK to the operator ( $\mathrm{S}$-ESAK-O) per applied Gy $\times \mathrm{cm}^{2}$ during one coronary angiography session, in $10 \mathrm{~cm}$ increments within the height range of $140-200 \mathrm{~cm}$. Under these conditions we analysed the efficacy of the ceiling mounted $1.0 \mathrm{~mm}$ lead glass screen lengthened by the lead flap, of a helmet of $0.5 \mathrm{~mm}$ lead equivalence, and of both protection devices together.

We used Student's $t$ test to verify differences in continuous variables and expressed the significance at a probability level of $\mathrm{p}=0.05$.

\section{RESULTS}

Fluoroscopic local scatter radiation exposure to the operator's head

The primary scatter ESAK to the operator's unprotected head ( $170 \mathrm{~cm}$ body height) under conditions of low level fluoroscopy (image intensifier entrance dose rate of $0.30 \mu \mathrm{Gy} / \mathrm{s}$ for the $17 \mathrm{~cm}$ field) was highest for left anterior oblique (LAO) tube angulations (fig 4). Posterior-anterior (PA) angulations induced lower S-ESAK-O, and right anterior oblique (RAO) projections, the least. Cranial angulations (black symbols in the figures) apparently induced slightly, but not significantly, higher S-ESAK-O levels than caudal angulations (white symbols). Mean (SD) S-ESAK-O ratios were 23.1 (10.1) for LAO/ RAO, 6.4 (2.0) for LAO/PA, and 3.5 (1.2) for PA/RAO angulations. The greatest scatter ESAK to the operator's position was in the form of irradiation from the tube direction of $-40^{\circ}$ to $-60^{\circ}$ on the operator's left, but also from $0^{\circ}$ and a direction slightly to the right. Scatter radiation from $+60^{\circ}$ to $+120^{\circ}$ on the right side, however, was much lower.

\section{Benefit of $\mathbf{1} .0 \mathrm{~mm}$ lead screen and $\mathbf{0 . 5} \mathbf{~ m m}$ lead cap} Overall in vivo DAP to patients during coronary angiography $(\mathrm{n}=112)$ is the sum of all partial DAPs applied to them for the various tube angulations. ${ }^{18}$ We multiplied these partial in vivo DAPs by the S-ESAK-O per $\mathrm{Gy} \times \mathrm{cm}^{2}$, applied to the

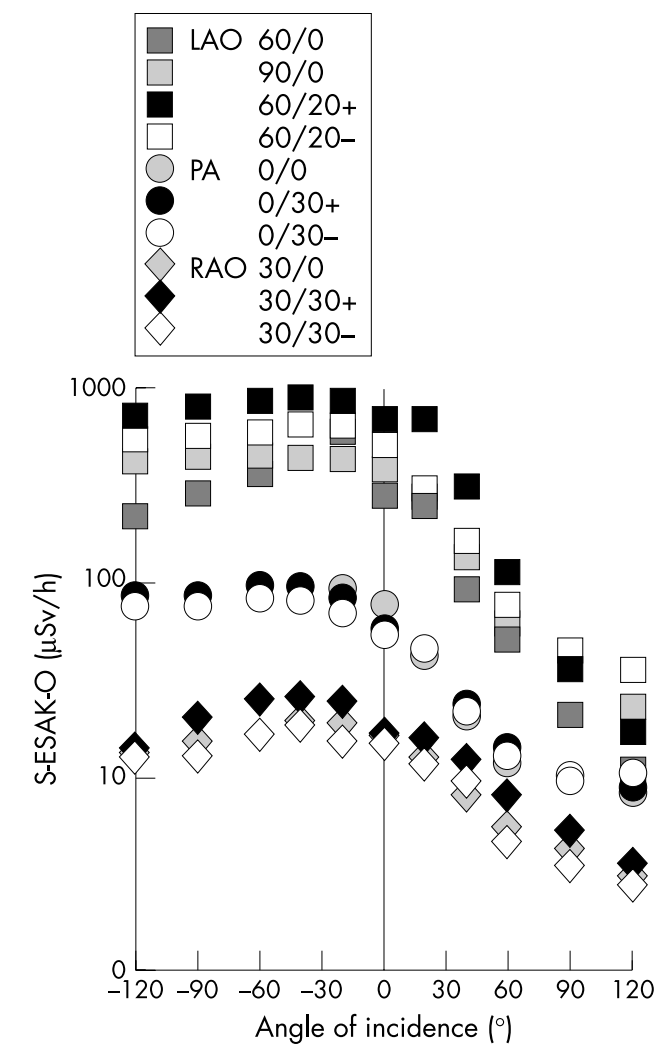

Figure 4 Dependence of primary S-ESAK to the operator's unprotected head ( $\mu \mathrm{Sv} / \mathrm{h}$ ) during low level fluoroscopy on tube angulation and angle of radiation incidence. $\mathrm{LAO}$, left anterior oblique; PA, posterior-anterior; RAO, right anterior oblique; S-ESAK-O, scatter entrance skin air kerma to the operator.

Rando phantom, for each respective tube angulation. The sum of these partial products represents the S-ESAK-O that reaches the operator from various angles of incidence during coronary angiography within a range of $140-200 \mathrm{~cm}$ body height. Dividing this value by the mean overall DAP of a coronary angiography, we obtained the mean S-ESAK to the operator per $\mathrm{Gy} \times \mathrm{cm}^{2}$ applied to the patient during coronary angiography (figs 5 and 6). Scatter ESAK to the operator's eyes without radiation protection was much higher at a line of vision of $-120^{\circ}$ to $0^{\circ}$ to the operator's left than was scatter ESAK coming from $\geqslant+60^{\circ}$ to the right side. The operator will be exposed, over the range of $140-200 \mathrm{~cm}$ body height, to mean (SD) levels of $2.1(0.5) \mu \mathrm{Sv} / \mathrm{Gy} \times \mathrm{cm}^{2}$ from the left, and to less than $240(40) \mathrm{nSv} / \mathrm{Gy} \times \mathrm{cm}^{2}$ from the right lines of vision $\geqslant+60^{\circ}$. As measurement points rose along the operator's height, the mean (SD) local operator radiation exposure decreased by 10 (3)\% per $10 \mathrm{~cm}$ (fig 5).

A $1.0 \mathrm{~mm}$ lead glass shield reduced mean (SD) S-ESAK-O/ DAP from coronary angiography from 1089 (764) to 54 (29) $\mathrm{nSv} / \mathrm{Gy} \times \mathrm{cm}^{2}$, depending on angle of incidence and body height. A $0.5 \mathrm{~mm}$ lead cap was effective in lowering measured levels to 1.8 (1.1) $\mathrm{nSv} / \mathrm{Gy} \times \mathrm{cm}^{2}$. Both devices together achieved attenuation to $0.5(0.1) \mathrm{nSv} / \mathrm{Gy} \times \mathrm{cm}^{2}$ (fig 6).

\section{Dependence of operator's scatter radiation exposure on line of vision}

To enable the patient to follow the interventional procedure, the monitors in many catheterisation laboratories are positioned in a line of vision of $-40^{\circ}$ to the operator's left. Regardless of tube angulation and of the absence or quality of lead protection, this line of vision (fig 7, black symbols) occasions higher S-ESAK-O levels to the operator's eyes and brain than does looking to the right at an angle of incidence of $+60^{\circ}$ (fig 7 , white symbols). With application of the protective devices, 


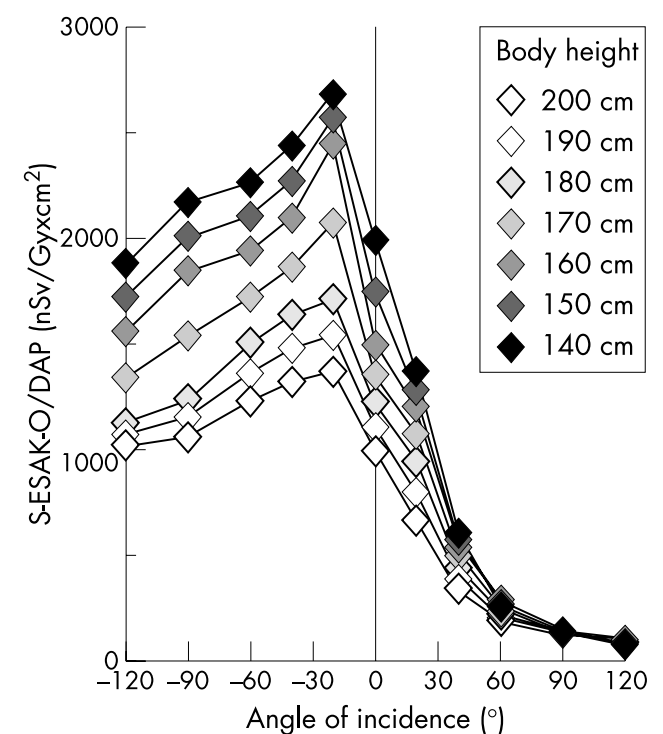

Figure 5 Scatter ESAK-O per dose-area product, applied to the phantom during coronary angiography $\left(\mathrm{nSv} / \mathrm{G} y \times \mathrm{cm}^{2}\right)$, as an inverse function of body height.

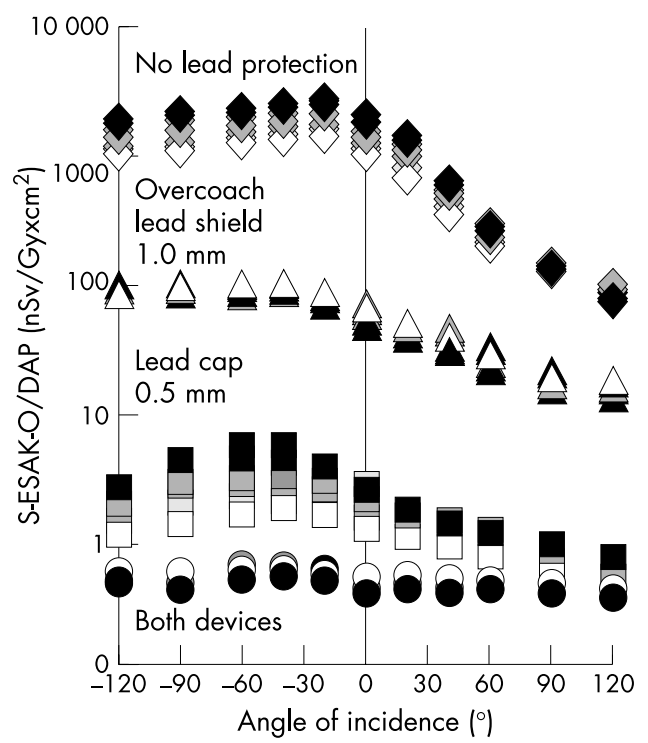

Figure 6 Scatter ESAK-O per dose-area product, applied to the phantom during coronary angiography $\left(\mathrm{nSv} / \mathrm{Gy} \times \mathrm{cm}^{2}\right)$, as a function of body height $(140 \mathrm{~cm}$ (black symbols) . . 200 cm (white symbols) and angle of radiation incidence within $-120^{\circ}$ to $+120^{\circ}$ to the operator's front. Effect of a $1.0 \mathrm{~mm}$ lead equivalent over couch shield, of a $0.5 \mathrm{~mm}$ lead equivalent cap, and of both devices together.

the ranking of radiation exposure according to tube angulation was no longer LAO $>$ PA $>$ RAO as demonstrated with no protection (black and white diamonds). Using both the glass shield and personal protection devices in the form of glasses and cap, scatter exposure to the operator's eyes and brain during fluoroscopy while looking to the right $\left(+60^{\circ}\right)$ will be reduced for all tube angulations to similar mean S-ESAK-O levels within 30-67 nSv/h (white circles). The lower parts of the operator's face unprotected by lead will be exposed to radiation levels of $800-4500 \mathrm{nSv} / \mathrm{h}$ with an overcouch lead glass shield (white triangles), and to $4500-110000 \mathrm{nSv} / \mathrm{h}$ without this protection (white diamonds).

\section{DISCUSSION}

Primary scatter ESAK to the operator's unprotected head is highest for left anterior oblique (LAO) tube angulations. This configuration is typically employed in invasive cardiology to

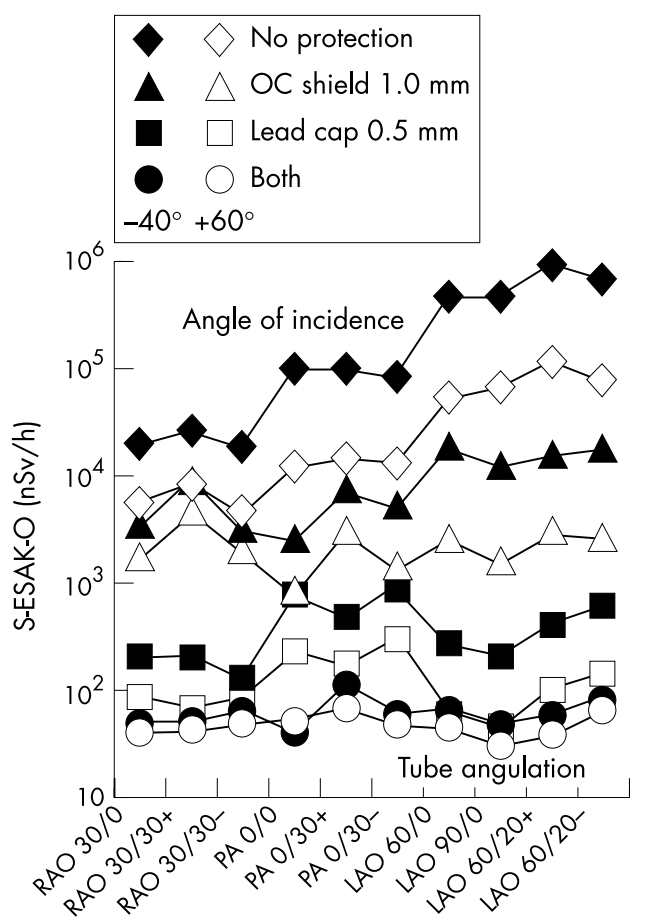

Figure 7 S-ESAK-O $(\mathrm{nSv} / \mathrm{h})$, as a function of tube angulation without lead protection (diamonds), and with the use of a $1.0 \mathrm{~mm}$ overcouch lead glass screen (triangles), of a $0.5 \mathrm{~mm}$ lead cap (squares), and of both devices together (circles). Effect of line of vision and monitor position in $-40^{\circ}$ tube direction (black), and $+60^{\circ}$ to the operator's right side (white).

document left main stem bifurcation (caudal LAO 60/20 spider view), the left anterior descending coronary artery (LAO 90/0), the bifurcation in the left anterior descending artery, and the diagonal branch (cranial LAO 60/20), and the left ventricle (LAO 60/0). Right anterior oblique (RAO) projections occasion the least radiation exposure. Mean S-ESAK-O ratios of LAO/RAO angulations to the operator's brain were within 4.6 to 38.2 , and ranged above reported ratios-that is, 2.6 to 12.4 with respect to total body height. ${ }^{18}{ }^{19}$ Cardiologists should consequently limit fluoroscopic LAO projections and shorten cinegraphic LAO documentation whenever possible. The highest S-ESAK-O is of course emitted from the tube direction to the operator's left, whereas scatter radiation from $>+60^{\circ}$ to the right is much lower. In order to protect lenses of the eyes and the brain, operators should attempt to work with monitors positioned to the right (fig 3).

In this study we measured mean S-ESAK-O/DAP levels of 2.1 (0.5) $\mu \mathrm{Sv} / \mathrm{Gy} \times \mathrm{cm}^{2}$ irradiating from the isocentre direction, with calculations based on all tube angulations used during coronary angiography. These results were significantly lower than the occupational doses of $8.4 \mu \mathrm{Sv} / \mathrm{Gy} \times \mathrm{cm}^{2}$ reported for a modern catheterisation system. ${ }^{12}$ However, several methodological differences explain this higher stray radiation/DAP measured by other researchers. The distance to the isocentre in other studies was $\leqslant 75 \mathrm{~cm}(v 100 \mathrm{~cm}$ in our catheterisation laboratory), dose measurements were done at $150 \mathrm{~cm}(170 \mathrm{~cm}$ in our laboratory), and operators did not consistently use low level modes as practised in the present study. For comparable circumstances with the operator's position at a distance of $1 \mathrm{~m}$ to the isocentre, for $150 \mathrm{~cm}$ above ground, and for LAO $90^{\circ} / 0^{\circ}$ tube angulation, our determined stray radiation level of $4.7 \mu \mathrm{Sv} / \mathrm{Gy} \times \mathrm{cm}^{2}$, measured towards the isocentre, correlates well with published stray radiation levels of $4-8 \mu \mathrm{Sv} / \mathrm{Gy} \times \mathrm{cm}^{2}$ for this exposure intensive tube angulation. ${ }^{80}$

Modern coronary angiography and percutaneous transluminal coronary angioplasty, as most recently reported, induce mean (SEM) DAPs of 62 (28) Gy $\times \mathrm{cm}^{2}, 21-26$ and 85 (34) $\mathrm{Gy} \times \mathrm{cm}^{2},{ }^{21} 2324$ respectively. The patient's DAPs and, in 
turn, the operator's stray radiation vary greatly, depending on the $x$ ray system employed, the operator's experience, the protocol, and the efficacy and acceptance of protection devices. Unfortunately, “ ... many interventionists are not aware of the potential for injury from procedures, their occurrence, or simple methods for decreasing their incidence utilising dose control strategies." $^{\prime 8}$ Staff doses can be considerably increased if inappropriate $x$ ray equipment or inadequate personal protection is used. ${ }^{12}$

Operators in a high volume catheterisation laboratory with a cumulative yearly workload of 1000 interventions, $40 \%$ of them typically being percutaneous transluminal coronary angioplasties, will subject their patients to a yearly cumulative radiation load of approximately $71200 \mathrm{~Gy} \times \mathrm{cm}^{2}$. Without lead protection, they will be exposed over the range of 140-200 cm body height to mean (SD) levels of 146 (38) mSv from the left sided lines of vision, down to less than 17 (3) mSv from right sided angles of incidence of $\geqslant+60^{\circ}$. Greater body height reduces the mean operator's head exposure by approximately $1 \% / \mathrm{cm}$ (fig 5). In good agreement with these calculations, the published mean entrance skin dose per coronary angiography to the lens of the operator's eye under the same workload would produce a mean (SEM) local annual radiation exposure of more than 165 (97) mSv. ${ }^{14-12}$ This level reflects the fact that coronary interventions typically include not only coronary angiography but also radiation intensive percutaneous transluminal coronary angioplasty. Such exposure levels exceed the recommended occupational limit of $150 \mathrm{mSv} / \mathrm{year}$ for the lens of the eye. This fact has prompted discussion in the literature of the relevance of these levels with respect to above normal frequencies of cataract development and brain cancer observed among interventionists. ${ }^{13}{ }^{15}$

These data should motivate cardiologists to make every effort to reduce such high exposure to their eyes and brain by application of the means of protection examined in the present study - that is, the use of both a $1.0 \mathrm{~mm}$ lead screen and a $0.5 \mathrm{~mm}$ lead cap. This recommended solution achieved a reduction of mean S-ESAK-O levels to $1.2(1.4) \times 10^{-3}$ of baseline. However, these results can vary according to the $x$ ray systems used, the catheterisation protocols, and the operator's correct use of the individual radiation protection devices.

Unexpectedly, a cap with only $0.5 \mathrm{~mm}$ lead equivalence was more protective than an overcouch shield with $1.0 \mathrm{~mm}$ lead equivalence (fig 6). This finding indicates that a significant amount of secondary scatter radiation, reflected from the laboratory walls, may reach the operator's head, despite the presence of a ceiling mounted lead glass shield designed to protect the face and head from primary scatter radiation from the patient.

Without any protection, or with $1.0 \mathrm{~mm}$ lead equivalent overcouch protection alone, the monitor position typically determines the operator's predominant line of vision in invasive cardiology. Regardless of tube angulation, the lowest S-ESAK-O will typically occur in a line of vision toward the foot of the table (fig 7). The use of additional $0.5 \mathrm{~mm}$ lead equivalent caps and glasses reduces such dependence on monitor position and the operator's line of vision. Under conditions of optimised radiation protection as outlined here, the operator's mean head exposure levels during fluoroscopy will range below the individual effective dose from environmental background radiation of 200-300 nSv/h.

At the same time, we did not take into account the S-ESAK-O fraction resulting from scattering around personal lead garments from the unprotected lower parts of the operators' face, up to their brain and eyes. Anatomical and technical circumstances render these levels hardly measurable with the ESAK acquisition systems currently in use. Even under conditions of optimised radiation protection of the head region as outlined in this study, looking toward the foot of the table $\left(+60^{\circ}\right)$ nevertheless exposes the lead-unprotected lower parts of the operator's face to considerable mean radiation levels - that is, to 2300 (1050) nSv/h (white triangles) and 35600 (37 100) nSv/h (white diamonds) in the presence and absence of an overcouch lead glass shield, respectively. We determined that looking towards the tube exposes the lower parts of the face to levels 4-10 times greater than does looking rightwards (fig 7). Optimal minimisation of this fraction would be possible through an improved lead helmet, including protection of nose and chin regions. The additional efficacy of a lead cap with respect to protection from stray radiation, as evidenced in this study, may encourage interventionalists to use one, especially as this cap is hardly more uncomfortable to wear than the conventionally recommended lead apron and lead glasses.

\section{Authors' affiliations}

E Kuon, J Birkel, M Schmitt, Department of Cardiology, Klinik Fraenkische Schweiz, Ebermannstadt, Germany

J B Dahm, Department of Internal Medicine, Ernst Moritz Arndt University, Greifswald, Germany

\section{REFERENCES}

1 Miller SW, Castronovo FP.Radiation exposure and protection in cardiac catheterisation laboratories. Am J Cardiol 1985;55:171-6.

2 CEC Council. Directive 97/43/Euratom of 30 June 1997. Article 4: On health protection of individuals against the dangers of ionising radiation in relation to medical exposure. Euratom Amtsblatt 1997:L180:22-7.

3 ICRP. Recommendations of the International Commission on Radiological Protection. ICRP Publication 60. Oxford: Pergamon Press, 1991:126,153,172.

4 Balter S, Sones FM, Brancato R. Radiation exposure to the operator performing cardiac angiography with U-arm systems. Circulation 1978;58:925-32.

5 Folkerts KH, Münz A, Jung S. Estimation of radiation exposure and radiation risk to staff of cardiac catheterization laboratories. $Z$ Kardiol 1997;86:258-63.

6 Karppinen J, Parviainen T, Servomaa A, et al. Radiation risk and exposure of radiologists and patient during coronary angiography and percutaneous transluminal coronary angioplasty. Radiat Prot Dosimetry 1995;57:481-5.

7 Watson LE, Riggs MW, Bourland PD. Radiation exposure during cardiology fellowship training. Health Phys 1997;73:690-93.

8 Valentin J. Avoidance of radiation injuries from medical interventional procedures. Ann ICRP 2000;30:7-67.

9 Dash H, Leaman DM. Operator radiation exposure to patients undergoing percutaneous transluminal coronary angioplasty. J Am Coll Cardiol 1984;4:725-8

10 Jeans SP, Faulkner K, Love HG, et al. An investigation of the radiation dose to staff during cardiac radiological studies. Br J Radiol 1985;58:419-28.

11 McParland MB, Nosil J, Burry B. A survey of the radiation exposures received by the staff at two cardiac catheterization laboratories. $\mathrm{Br} J$ Radiol 1990;63:885-8.

12 Vano E, Gonzalez L, Guibelalde E, et al. Radiation exposure to medical staff in interventional and cardiac radiology. Br J Radiol 1998;71:954-60.

13 Renaud L. A 5-year follow up of the radiation exposure to in-room personnel during cardiac catheterization. Health Phys 1992;62:10-15.

14 Vano E, Gonzalez L, Bebeytez F, et al. Lens injuries induced by occupational exposure in non-optimised interventional radiology laboratories. Br J Radiol 1998;71:728-33.

15 Finkelstein MM. Is brain cancer an occupational disease of cardiologists? Can J Cardiol 1998;14:1385-8.

16 Marshall NW, Faulkner K. The dependence of the scattered radiation dose to personnel on technique factors in diagnostic radiology. $\mathrm{Br} J$ Radiol 1992;65:44-9.

17 Williams JR. Scatter dose estimation based on dose-area product and the specification of radiation barriers. Br J Radiol 1996:69:1032-7.

18 Kuon E, Schmitt M, Dahm JB. Significant reduction of radiation exposure to operator and staff during cardiac interventions by analysis of radiation leakage and improved lead shielding. Am J Cardiol 2002;89:44-9.

19 Pitney MR, Allan RM, Giles RW, et al. Modifying fluoroscopic view reduces operator exposure during coronary angioplasty. J Am Coll Cardiol 1994;24:1660-3.

20 Marx DL, Balter S. The distribution of stray radiation patterns in a cardiac catheterization laboratory [abstract]. Health Phys 1995;68(suppl 6): 84 .

21 Cusma JT, Bell MR, Wondrow MA, et al. Real-time measurement of radiation exposure to patients during diagnostic coronary angiography and percutaneous interventional procedures. J Am Coll Cardiol 1999;33:427-35.

22 Clark AL, Brennan AG, Robertson L, et al. Factors affecting patient radiation exposure during routine coronary angiography in a tertiary referral centre. Br J Radiol 2000;73:184-9. 
23 Fransson SG, Persliden J. Patient radiation exposure during coronary angiography and intervention. Acta Radiol 2000;41:142-4.

24 Van de Putte S, Verhaegen F, Taeymans Y, et al. Correlation of patient skin doses in cardiac interventional radiology with dose-area product. Br J Radiol 2000;73:504-13.

25 den Boer A, de Feijter PJ, Serruys PW, et al. Real-time quantification and display of skin radiation during coronary angiography and intervention. Circulation 2001:104:1779-84.
26 Lobotessi H, Karoussou A, Neofotistou V, et al. Effective dose to a patient undergoing coronary angiography. Radiat Prot Dosimetry 2001;94:173-6.

27 Bernardi G, Padovani R, Morocutti G, et al. Clinical and technical determinants of the complexity of percutaneous transluminal coronary angioplasty procedures: analysis in relation to radiation exposure parameters. Cathet Cardiovasc Intervent 2000;51:1-9.

\section{IMAGES IN CARDIOLOGY}

\section{Transcatheter closure of direct communication between right pulmonary artery and left atrium using Amplatzer device}

$A^{s}$ 5 year old girl presented with mild cyanosis since birth. graphy revealed a prominent round opacity at the upper right heart border. Transthoracic echocardiography showed a dilated proximal right pulmonary artery. Echocontrast injected into a peripheral vein opacified the right heart, then passed rapidly to the left atrium. Positive pressure ventilation during cardiac catheterisation caused further systemic desaturation to 54\%. Pulmonary artery angiography demonstrated a large fistula between the proximal right pulmonary artery and the left atrium. The communication tapered at its midpoint to a minimum diameter of $9.8 \mathrm{~mm}$ (below left). The fistula was crossed from the right heart with a long transseptal sheath and a $14 \mathrm{~mm}$ Amplatzer muscular ventricular septal defect occluder was deployed at its narrowest point (below centre). Oxygen saturation increased immediately to $100 \%$. Repeat angiography demonstrated complete occlusion of the Systemic oxygen saturation was $80 \%$. Chest radio-

fistula. The device did not obstruct the right pulmonary artery and remained stable on release.

Direct communication between the right pulmonary artery and the left atrium is a rare congenital cardiac malformation. It may present in the neonatal period with intense cyanosis requiring urgent intervention. If desaturation is less severe, presentation may be delayed to later in childhood or even adult life. Early repair should be performed to avoid complications, particularly systemic emboli, cerebral abscess, and rupture of aneurysmal communications. Although surgical ligation or division is the accepted treatment, transcatheter coil occlusion has been described in one neonate and Amplatzer device occlusion offers an alternative for larger communications.
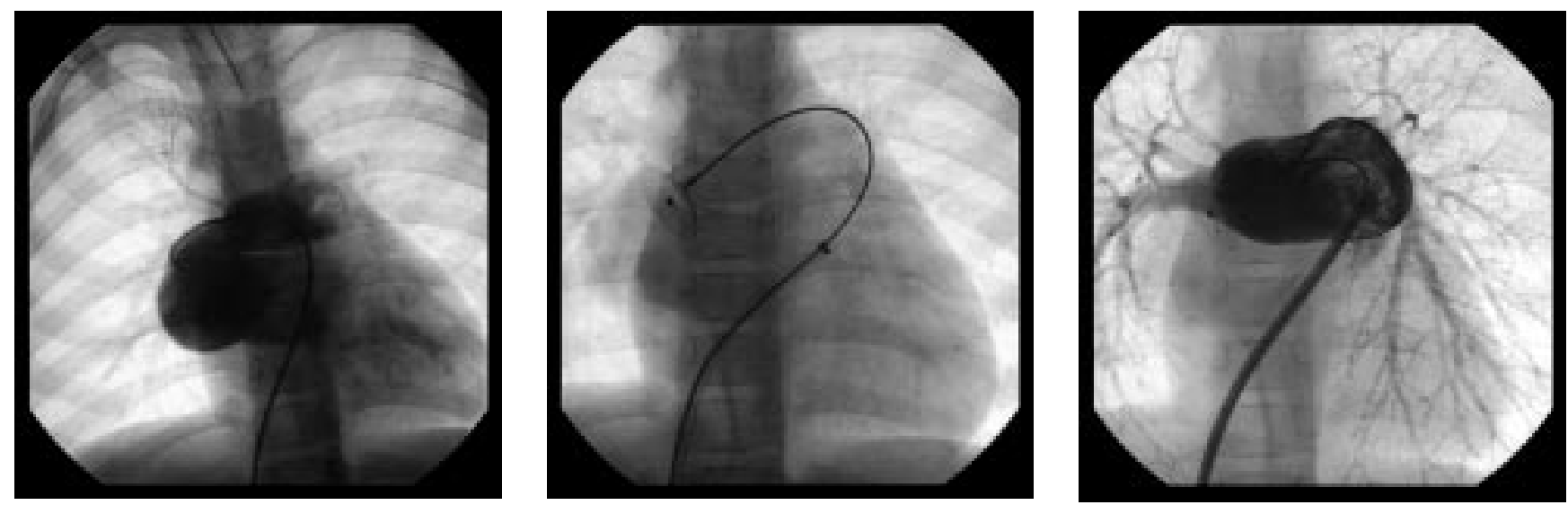